\title{
La enfermería frente a la salud y la enfermedad
}

La salud y la enfermedad son situaciones reales y complejas de personas y grupos en una sociedad. Los saberes, creencias y necesidades conducen a las personas a adoptar las medidas pertinentes para prevenir o curar una enfermedad.

A pesar de que en el mundo se originan constantes cambios tecnológicos, sociales, o políticos, el hombre no ha logrado controlar las adversidades sanitarias, por el contrario, cada día se aprecian fenómenos que deterioran aun más la salud. Esta situación es muy compleja, porque en la ecuación no solo suma la presencia o ausencia del daño, sino la capacidad del hombre para prevenir y controlarlo, agregado a ello, la falta de conciencia sanitaria.

El cuidado de la salud, como práctica social, tiene su génesis y se estructura a través del saber cultural, de personas, sociedades e instituciones. En los diferentes grupos sociales de los diversos sistemas de salud existentes, se corresponden con formas particulares de comprender y controlar los fenómenos durante el proceso salud -enfermedad. La enfermera, al brindar el cuidado de enfermería, tiene la obligación de alinear su visión de cuidado no solo al sistema sanitario, sino a la visión de salud de las personas en todo contexto donde se desenvuelve (1).

Es importante reflexionar sobre el rol del profesional de Enfermería en este contexto, su labor ¿es curativa?, ¿que deberá hacer la enfermera frente a una sociedad que ya no es la misma de hace 10 años?, hay que analizar que las enfermedades no solo son físicas sino mentales, y que están incidiendo de manera incontrolada en la salud de las personas, teniendo como consecuencia un país menos productivo, con incremento del gasto e incertidumbre familiar.

El cuidado de Enfermería es un proceso complejo que delimita las intervenciones necesarias para resolver o mitigar el problema. Estas intervenciones se encuentran en la categoría de promoción de la salud o prevención y manejo de la enfermedad. Si la persona tiene riesgo de padecer un problema específico, las intervenciones deberán abordar la prevención del riesgo, y corresponden a la categoría de protección de la salud; cuando la persona es relativamente sana pero se realizan actividades de promoción de la salud, en ámbitos de nutrición, ejercicio, sueño, moderación de los estilos de vida, control del estrés y apoyo social. (2)

En el Perú, las enfermedades de tipo social como la tuberculosis, el cáncer, la enfermedad renal, y otras enfermedades crónicas, constituyen la principal carga de enfermedad, las condiciones de vida de las personas influyen de manera explícita en la salud de las personas y, por lo tanto, en su calidad de vida. Estas enfermedades están relacionadas al consumo de tabaco, al abuso en el consumo de alcohol, la dieta carente de los nutrientes indispensables, la inactividad física, y el contacto con carcinógenos del ambiente (3).

Como se observa, para la Enfermería es un reto frente a los cambios que experimenta la población y, por lo tanto, demanda de mayor énfasis en la mejora de aspectos relacionados con la promoción y prevención sanitaria. Por lo tanto, surge la necesidad de dar respuesta multisectorial frente a los problemas sanitarios, es por ello que quienes se encuentran en la labor docente deben y deberán formar a futuros profesionales basado en un enfoque holístico, teniendo en cuenta que el cuidado enfermero va más allá de atender a la persona enferma, porque el desarrollo de una enfermedad involucra un cambio en la interrelación de la persona con su entorno.

\section{Olga Perea Canchares}

\footnotetext{
1. Revista de Enfermería. Disponible en : http://www.encolombia.com/medicina/enfermeria/enfermeria5202-enfermeria2

2. Lunney M. Razonamiento crítico para alcanzar resultados de salud positivos. España. Ed. ELSEVIER. 2011

3. López Centeno. Vigilancia de Enfermedades no transmisibles. Boletín epidemiológico. RENACE. 2011 (20). Disponible en :

http://www.dge.gob.pe/boletines/2011/20.pdf
} 